\title{
Time Lost from Play in Foot and Ankle Injuries of Professional Soccer Players
}

\section{Haluk H. Oztekin* and Bulent Zeren}

Orthopaedic Surgeons, Private Clinic for Sports Traumatology and Orthopaedics, 1738 Sokak, No: 10, Karsiyaka, Izmir, Turkey

\begin{abstract}
Objective: Ankle and foot injuries are common in professional soccer players, but the relation between injury severity and time lost from play is not well known. The aim of this study is to investigate the relationship between diagnosis, injury severity and time lost to play of professional soccer players with severe ankle and foot injuries with reviewing the recent literature.
\end{abstract}

Design: Prospective evaluation of retrospectively collected data and review of the literature.

Setting: Primary private practice.

Patients: The medical records of two hundred lower extremity injuries of professional soccer players who admitted to our private clinic during the 2003-2004 professional national soccer league season were reviewed. Collected data of sixty-six players with severe ankle and foot injuries were included in the study. Type of injury, diagnosis, treatment, injury severity and finally, time lost from play were evaluated from the medical records. Injury severity ('severe' if $>28$ days, 'moderate' if between 8-28 days) and time lost from play were calculated from medical records and by telephone interviews with the players.

Results: Most injuries ( $n=20,32 \%$ ) occurred during player-to-player contact. The most common diagnosis was ankle sprain $(30.3 \%)$ with anterior talofibular ligament injury. Most $(55 \%)$ hindfoot injuries were Achilles tendinopathy with or without rupture. Treatment was surgical in 23 patients (35\%). The mean time lost from play for players with severe foot and ankle injuries was 61days (range 21-240 days); after Achilles tendon ruptures, the mean time lost was 180 days. Injury severity was severe (>28 days lost from play) in $64 \%$ patients and moderate (8-28 days lost from play) in $36 \%$ patients.

Conclusion: Time lost to play can dramatically increase by the presence of severe ankle and foot injuries. Serious ankle and foot injuries in this study resulted in players being out of professional competition for about two months.

\section{Introduction}

Soccer carries a certain risk of injury for its participants, from 13 to 35 injuries per 1000 player-hours of competition [1]. However, less is known about the risk factors, mechanisms, injury severity of soccerrelated injuries and their resulting time lost to play while players recover [2,3]. In addition, no consensus exists about study design, data collection, and injury definitions in the epidemiological studies of soccer injuries to date [3].

After the thigh, the feet and ankles are the most common locations for injury (19\% and $7 \%$ of match injuries) in professional players during competition, with an incidence of 39 injuries per thousand hours of competition [4]. Soccer players with 'footballer's ankle' develop ankle osteoarthritis at a much higher rate than the general population $[5,6]$. Identifying the causes, type of injury and injury severity of foot and ankle injuries in soccer players may influence efforts for preventive strategies [7].

Some studies have explored the mechanism and type of injury in soccer related ankle and foot injuries with or without video-based analyses, however much less is known about the real diagnosis, treatment and true time loss [7-13]. The aim of this study was to investigate the relationship between diagnosis, injury severity and time lost to play of professional soccer players with severe ankle and foot injuries.

\section{Methods}

Retrospectively, records of 200 professional soccer players with a primary complaint of having injured their lower extremity during practice or competition were reviewed. All players presented for care to our private sports/orthopaedic clinic during the 2003-2004 professional national outdoor soccer league season and were cared for by one orthopaedic surgeon. Sixty-six were found to have had severe ankle and/or foot injuries according to Chomiak [10] criteria and included in the study. Injury severity was categorized as minor (1-7 days absence), moderate ( $8-28$ days), and severe ( $>28$ days) [11]. The primary mechanism and type of injury were determined by patient history.

Injuries were classified anatomically as being in the ankle, midfoot, or hindfoot. Achilles tendinopathy and ruptures were classified as hindfoot injuries. The Orava [14] modification [3] of injury classification was used. After clinical examination, conventional radiographs were obtained as per the Ottawa [15] criteria. Ultrasonography (USG) with a high-resolution probe with or without dynamic scanning was performed when needed by a musculoskeletal ultrasonographer experienced in sports trauma scanning. Magnetic resonance imaging (MRI) was performed if chronic overuse syndrome, impingement syndrome, bone bruise or ankle joint instability was

*Corresponding author: Haluk H. Oztekin, MD, Orthopaedic Surgeon, 6345 Sokak, No: 6/11 35540, Karsiyaka, Izmir, Turkey, Tel: +902324633315; Fax +902324647377; GSM: +905323122404; E-mail: hhoztekin@isbank.net.tr

Received December 13, 2011; Accepted January 25, 2012; Published January 29, 2012

Citation: Oztekin HH, Zeren B (2012) Time Lost from Play in Foot and Ankle Injuries of Professional Soccer Players. J Sport Medic Doping Studie S2:002. doi:10.4172/2161-0673.S2-002

Copyright: (C) 2012 Oztekin $\mathrm{HH}$, et al. This is an open-access article distributed under the terms of the Creative Commons Attribution License, which permits unrestricted use, distribution, and reproduction in any medium, provided the original author and source are credited. 
suspected clinically and radiographically. The same surgeon performed all surgical treatments and prescribed rehabilitation treatments to be performed by one sports physiotherapist. The "return to play" decision was made after completing rehabilitation, a final clinical examination, and a field test.

The time lost from participation was calculated from our own medical records and confirmed by telephone interviews with the each player. After returning to the field, follow-up examinations were performed over the course of two months to determine if reinjury had occurred. Results were analysed and discussed with recent literature.

\section{Results}

Of 200 patients with lower extremity soccer-related injuries, 66 had severe ankle and foot problems (33\%). Sixty-one patients of 66 were male and the mean age was 23 years old (range 17 and 31 years old). Patient demographics are summarized in Table 1. The majority (61\%) injured themselves during a competition. No ankle bracing, taping, bandages or orthoses were used in any patient, but all of them had worn shin guards at the time of injury. All matches were played on natural grass. The injury mechanism was direct player-to-player contact (32\%), overuse (26\%), tripping on the grass $(10,5 \%)$, landing $(7,5 \%)$, jumping and jumping/landing (7,5\%), tackling (4,5\%), being tackled $(4,5 \%)$, shooting (3\%), kicking and kicking/shooting (3\%), sprinting (1,5\%). Most (59\%) had injuries of the right foot/ankle, and 79\% were in the dominant extremity.

The anatomical sites of injury were the ankle in $56 \%$, hindfoot in $30 \%$ and midfoot in $14 \%$. The majority of injuries were ankle sprains and anterior talofibular ligament (ATFL) lesions $(n=20)$; others were overuse impingement syndromes $(n=10)$, Achilles overuse with strain ( $\mathrm{n}=11$; tendinopathy in 6 hindfeet of 5 players, and 5 ruptures), metatarsal fractures $(n=7)$, ankle contusions $(n=3)$, malleolus fractures $(\mathrm{n}=3)$, symptomatic os trigonum $(\mathrm{n}=3)$, osteochondral talar lesions $(n=2)$, fracture dislocation of the ankle $(n=1)$, tibial shaft fracture $(\mathrm{N}=1)$ and plantar fasciitis $(n=1)$. Achilles tendon ruptures happened during jumping and jumping/landing in three of five players during training.

Twenty-seven players with ankle sprains had X-rays and musculoskeletal USG performed. Eleven players had X-rays only. Tendinopathies were confirmed by USG only in nine players. Nineteen players needed MRI (Table 1). No scintigraphy (bone scan) was performed.

Treatment was surgical in 23 patients (35\%); in four of these, ankle arthroscopy was performed, followed by early rehabilitation. Others were treated with only an aggressive sports rehabilitation program. "Return-to-play" decisions were made after an on-field observational test (eg. plyometric exercises). All players were contacted by telephone and confirmed the "return-to-play" date.

The mean time lost to play was 61 days (range 21-240 days). The mean time lost to play after an Achilles tendon rupture was 180 days. When Achilles tendinopathy and ruptures were excluded from the study, the overall mean time lost to play was 48 days. In 21 "player-toplayer contact" injuries, the mean time lost to play was 56 days and the injury severity 'major', in 17 players with 'overuse injuries', a similar mean time lost to play was found (56 days). Injury severity was severe ( $>28$ days lost to play) in $64 \%$ of patients and moderate (8-28 days lost to play) in $36 \%$. No player experienced a reinjury in the two-month follow-up period.

\section{Discussion}

The most common injury mechanisms for foot and ankle injuries in soccer are direct contact in $58 \%$ of our patients, and in $59 \%$ in a study among professional English football players [12]. As found in similar studies, the dominant foot is most commonly injured and the majority of injuries happen during competition rather than during training $[16,17]$. Wong and Hong [13] described this as "the higher the speed of play, the higher the rate of injury".

According to Woods et al. [12], ankle sprains occurred most often during tackles (54\%). Biomechanical studies have shown that the ATFL is the first ligament to be tensed and rupture when forced inversion of the ankle occurs [7]. Our findings correlate with the other studies $[1,4,7,12,13]$ suggesting that the typical responsible mechanism is inversion. Because our results relied on the player's recollection of the event, the position of the foot as the injury occurred was not as clear as it might have been on a video replay. (Table 1)

Achilles tendinopathy and ruptures are sometimes classified as 'lower leg injuries' rather than foot and ankle injuries, but in a recently published review, Achilles tendinopathies and ruptures were categorized as hindfoot problems [18]. Hindfoot injuries occurred frequently (30\% of all ankle-foot injuries) in the players in our series, with most (55\%) being Achilles tendinopathy and ruptures. Although these injuries caused a time lost to play of 180 days in our study, few studies mention Achilles tendinopathy and rupture among professional soccer players $[10,11,19,20,21]$. The frequency of Achilles tendon ruptures varies considerably from country to country, perhaps due to the variation in sports traditions and popularity [21], which may explain the small number of studies in the literature.

Although we have classified Achilles ruptures in "strain" group, we believe that they must be categorized as both overuse injuries and strains. Achilles tendinopathy could be a main risk factor in Achilles ruptures. In a recent study, Mahieu et al. [22] described intrinsic risk factors that play an important role in Achilles tendon overuse injuries. Other well known risk factors are hard ground, resumption of training after a break, poor footwear and increased intensity of training and running [23]. Therefore, paying attention to the player's plantar flexor strength and amount of dorsiflexion excursion [an intrinsic risk factor mentioned by Mahieu [22]], minimising overtraining in the pre- or mid-season, wearing better shoes and playing on suitable ground may prevent such injuries.

While few studies $[10,11,24]$ describe the mechanism and type of injury in soccer-related ankle and foot injuries, even fewer elaborate on the true diagnosis and real time loss. Hoy et al. [24] reported a very low "average duration of lost work time" as five days in 715 soccer injuries in their epidemiological study, while Chomiak et al. [10] reported a mean 57 day duration of absence. However, both of these studies were focused on general trauma in soccer players rather than ankle/footrelated injuries. Our injury severity was higher than in other published studies $[10,17,24]$.

Video-based investigations or baseline forms [3] may be suitable for recording the mechanism and type of injuries, but not for the final diagnosis and time lost to play. Recording the true diagnosis and time lost to play are also problematic though: recovering original on-field injury records, harmonising original injury records with the final diagnosis, following-up a player who has changed physicians, and crude estimations of the period away from play may result in inaccurate data. In most studies to date, the diagnoses, time lost to play and injury severity calculations were made by estimations $[1,4,7-9,24]$ rather than from medical and on-field playing records [3].

The populations surveyed and the definitions of injury severity and time lost to play vary between studies, making comparisons 
Citation: Oztekin HH, Zeren B (2012) Time Lost from Play in Foot and Ankle Injuries of Professional Soccer Players. J Sport Medic Doping Studie S2:002. doi:10.4172/2161-0673.S2-002

Page 3 of 5

difficult [9]. For example, most epidemiological studies report general soccer trauma $[10,17,20,24]$ with a few exceptions reporting specific anatomical sites $[4,6,7,21]$. We preferred using the UEFA model for interpreting the time lost to play and injury severity [3]. We agree with Ekstrand [25] that the real time loss must be "an injury that occurred during a scheduled training session or match that caused absence from the next training session or match". Time lost to play was dramatically increased by the presence of an Achilles rupture or fracture, and was especially lengthy in player-to-player contact and overuse injuries. One survey among professional, adolescent, adult and child soccer players found most ankle and foot injuries to be minor [13]. Our patients were likely self-selected, most not seeking care at our sports medicine clinic for more minor injuries.

The limitations of this present study were its retrospective design and the lack of video recordings for determining the exact mechanism of injury. Although we calculated the time lost to play from our medical records and by telephone interviews, calculations from the attendance records of the teams would be more accurate. Patient based questionnaires, clinician based evaluation using objective criteria must

\begin{tabular}{|c|c|c|c|c|c|c|c|c|c|c|c|c|c|}
\hline 怘 & 迥 & 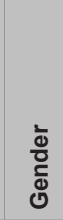 & $\begin{array}{l}\text { ய் } \\
\text { ய் } \\
\dot{~}\end{array}$ & 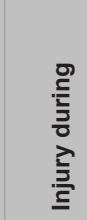 & 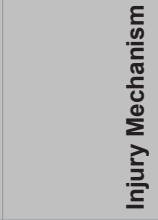 & $\frac{\frac{0}{x}}{\frac{c}{4}}$ & 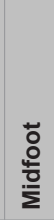 & $\begin{array}{l}\text { 艹 } \\
\frac{0}{0} \\
\text { 도 }\end{array}$ & 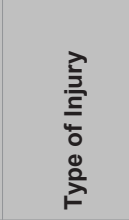 & 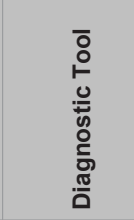 & $\begin{array}{l}\frac{n}{0} \\
0 \\
\frac{5}{0} \\
\frac{\pi}{0}\end{array}$ & 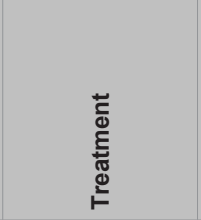 & 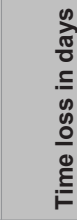 \\
\hline 1 & 27 & M & $\mathrm{R}$ & $\mathrm{T}$ & Sprinting & & & $\mathrm{R}$ & Strain & USG/MRI & Achilles rupture & Surg & 240 \\
\hline 2 & 31 & M & L & M & Tripping & & & L & Strain & USG/MRI & Achilles rupture & Surg & 180 \\
\hline 3 & 25 & M & L & M & Overuse & L & & & Other & $x$ ray & $\begin{array}{l}\text { Lat.mall. } \\
\text { pseudoarthrosis }\end{array}$ & Surg/Greft & 200 \\
\hline 4 & 27 & M & $R$ & M & Overuse & $R$ & & & Overuse & x ray & Footballer's ankle/lmp. & Arth/Surg & 45 \\
\hline 5 & 21 & M & $\mathrm{L}$ & M & $\mathrm{P} / \mathrm{P}$ & & L & & Fx & $\mathrm{x}$ ray & 1st Tarso/metatarsal fx. & Surg & 105 \\
\hline 6 & 26 & M & $\mathrm{R}$ & M & $\mathrm{P} / \mathrm{P}$ & $\mathrm{R}$ & & & Fx & x ray & Tibial shaft fx. & Surg & 240 \\
\hline 7 & 22 & M & $R$ & M & $\mathrm{P} / \mathrm{P}$ & $\mathrm{L}$ & & & Fx & $\mathrm{x}$ ray & Maisonneuve fx. & Surg & 150 \\
\hline 8 & 29 & M & $\mathrm{R}$ & M & Jumping & & & $\mathrm{R}$ & Strain & USG/MRI & Achilles rupture & Surg & 150 \\
\hline 9 & 27 & M & L & $\mathrm{T}$ & Overuse & & & L & Strain & x ray/USG & $\begin{array}{l}\text { Ach. Tendinopathy/O. } \\
\text { Trigonum }\end{array}$ & Surg & 150 \\
\hline 10 & 25 & M & L & $\mathrm{T}$ & $\mathrm{J} /$ Landing & & & L & Strain & USG/MRI & Achilles rupture & Surg & 180 \\
\hline 11 & 22 & M & L & M & Tackling & & L & & Fx & $\mathrm{x}$ ray & 5th metartarsal fx. & Surg & 90 \\
\hline 12 & 19 & M & L & $\mathrm{T}$ & Overuse & & & L & $F x$ & MRI & Sympt. os trigonum & Surg & 45 \\
\hline 13 & 21 & M & $\mathrm{R}$ & M & $\mathrm{b} / \mathrm{Tck} ?$ & & L & & Fx & $x$ ray & 5th metartarsal fx. & Surg & 150 \\
\hline 14 & 19 & M & $\mathrm{R}$ & M & Overuse & $\mathrm{R}$ & & & Overuse & MRI & $\mathrm{A} / \mathrm{L}$ impingement & Surg & 90 \\
\hline 15 & 25 & M & L & $\mathrm{T}$ & Landing & $\mathrm{R}$ & & & Strain & x ray/USG & $\begin{array}{l}\text { Peroneal tendon } \\
\text { luxation }\end{array}$ & Surg & 60 \\
\hline 16 & 26 & M & L & $\mathrm{T}$ & Overuse & L & & & Overuse & MRI & $\mathrm{A} / \mathrm{M}$ impingement & Arth & 60 \\
\hline 17 & 28 & M & L & M & Overuse & L & & & Overuse & MRI & Ant. impingement & Arth & 30 \\
\hline 18 & 27 & M & L & $\mathrm{T}$ & Tripping & L & & & Overuse & x ray/USG & ATFL sprain & Sport.Rehab. & 30 \\
\hline 19 & 30 & M & $\mathrm{R}$ & M & Overuse & & & $\mathrm{R}$ & Overuse & USG & Achilles tendinopathy & Sport.Rehab. & 30 \\
\hline 20 & 19 & M & $\mathrm{L}$ & $\mathrm{T}$ & $\mathrm{K} / \mathrm{S}$ & $\mathrm{L}$ & & & Contusion & MRI & Bone bruise/Lat.mall. & Sport.Rehab. & 60 \\
\hline 21 & 23 & M & L & $\mathrm{T}$ & Tripping & L & & & Sprain & x ray/USG & Deltoid lig. Sprain & Sport.Rehab. & 30 \\
\hline 22 & 20 & M & L & M & $\mathrm{P} / \mathrm{P}$ & L & & & Sprain & $\mathrm{x}$ ray/USG & ATFL sprain & Sport.Rehab. & 90 \\
\hline 23 & 27 & M & $R$ & M & Tripping & $\mathrm{R}$ & & & Fx/Sprain & x ray/USG & $\begin{array}{l}\text { Lat.mall.fx/Delt.lig. } \\
\text { rupture }\end{array}$ & Surg & 150 \\
\hline 24 & 24 & M & $R$ & M & $\mathrm{P} / \mathrm{P}$ & & $\mathrm{R}$ & & Strain & x ray/USG & $\begin{array}{l}\text { Peroneal Tendon } \\
\text { strain }\end{array}$ & Sport.Rehab. & 60 \\
\hline 25 & 27 & M & L & M & Overuse & & & L & Overuse & MRI & Post. Impingement & Art/Surg & 30 \\
\hline 26 & 21 & M & $R$ & M & Overuse & & & $R$ & Overuse & MRI & Post. Impingement & $\begin{array}{l}\text { Local Inj. } \\
\text { Sp.Rehab }\end{array}$ & 30 \\
\hline 27 & 22 & M & $\mathrm{R}$ & M & Landing & $\mathrm{R}$ & & & Sprain & x ray/USG & ATFL Sprain & Sport.Rehab. & 45 \\
\hline 28 & 26 & M & $\mathrm{L}$ & $\mathrm{T}$ & Overuse & & & L & Overuse & USG/MRI & Achilles tendinopathy & Surg & 45 \\
\hline 29 & 17 & M & $\mathrm{R}$ & $\mathrm{T}$ & $\mathrm{P} / \mathrm{P}$ & & $\mathrm{R}$ & & Fx & $\mathrm{x}$ ray & 5th metartarsal fx. & Cast & 90 \\
\hline 30 & 19 & M & L & M & Overuse & & & L & Overuse & USG & Achilles tendinopathy & Sport.Rehab. & 21 \\
\hline 31 & 25 & M & $\mathrm{R}$ & M & $\mathrm{P} / \mathrm{P}$ & $\mathrm{R}$ & & & Sprain & $\mathrm{x}$ ray/USG & ATFL Sprain & Sport.Rehab. & 21 \\
\hline 32 & 33 & M & $R$ & $\mathrm{~T}$ & $\mathrm{P} / \mathrm{P}$ & $R$ & & & Sprain & x ray/USG & ATFL Sprain & Sport.Rehab. & 21 \\
\hline 33 & 32 & $M$ & $\mathrm{R}$ & M & $\mathrm{P} / \mathrm{P}$ & $\mathrm{R}$ & & & Sprain & x ray/USG & ATFL Sprain & Sport.Rehab. & 30 \\
\hline 34 & 25 & M & $\mathrm{R}$ & M & Tripping & $\mathrm{R}$ & & & Sprain & x ray/USG & ATFL Sprain & Sport.Rehab. & 21 \\
\hline 35 & 19 & M & $\mathrm{R}$ & $\mathrm{T}$ & Tackling? & L & & & Overuse & USG & Ganglion of peroneal Tendon & Surg & 30 \\
\hline 36 & 17 & M & $\mathrm{R}$ & M & $\mathrm{b} / \mathrm{Tck}$ & $\mathrm{R}$ & & & Contusion & x ray/USG & $\begin{array}{l}\text { Contusion/Post. } \\
\text { tibial tendon }\end{array}$ & Sport.Rehab. & 21 \\
\hline 37 & 16 & M & $\mathrm{R}$ & M & Overuse & $\mathrm{R}$ & & & Overuse & MRI & Post.Imping./O. Trigonum & Loc.Inj/Rehab. & 21 \\
\hline 38 & 27 & M & $R / L$ & $\mathrm{~T}$ & Overuse & & & $R / L$ & Overuse & USG & Achilles tendinopathy & Sport.Rehab. & 30 \\
\hline 39 & 26 & M & $\mathrm{R}$ & M & Shooting? & $\mathrm{R}$ & & & Sprain & x ray/USG & C/F Lig. Sprain & Sport.Rehab. & 30 \\
\hline
\end{tabular}




\begin{tabular}{|c|c|c|c|c|c|c|c|c|c|c|c|c|c|}
\hline 40 & 26 & M & $\mathrm{R}$ & $\mathrm{T}$ & Tripping & & & $R$ & Overuse & MRI & $\mathrm{P} / \mathrm{M}$ impingement & Sport.Rehab. & 21 \\
\hline $\begin{array}{l}\text { D } \\
\text { 心 } \\
\text { J }\end{array}$ & $\stackrel{0}{\circ}$ & 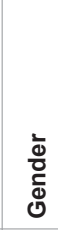 & $\begin{array}{l}\text { 爻 } \\
\text { ய } \\
\dot{\Xi ் ~}\end{array}$ & 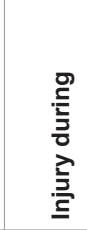 & 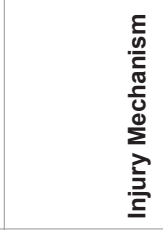 & $\frac{\frac{0}{x}}{\frac{\pi}{\alpha}}$ & 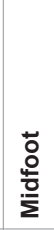 & $\begin{array}{l}\text { 뭉 } \\
\text { 응 } \\
\text { 오 }\end{array}$ & 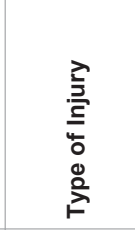 & 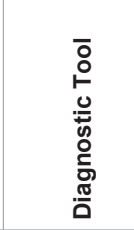 & $\begin{array}{l}\frac{n}{0} \\
\stackrel{0}{0} \\
\frac{\pi}{0} \\
\frac{\pi}{0}\end{array}$ & 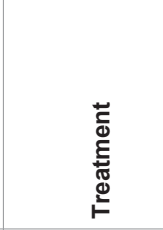 & 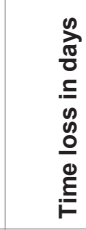 \\
\hline 41 & 18 & M & $\mathrm{R}$ & $M$ & $\mathrm{P} / \mathrm{P}$ & & & $\mathrm{R}$ & Overuse & MRI & $\mathrm{P} / \mathrm{L}$ impingement & Sport.Rehab. & 21 \\
\hline 42 & 18 & M & $\mathrm{R}$ & $\mathrm{T}$ & Tackling & & & $\mathrm{R}$ & Contusion & MRI & Bone bruise(talus) & Sport.Rehab. & 21 \\
\hline 43 & 22 & M & $\mathrm{L}$ & M & $\mathrm{b} / \mathrm{Tck}$ & L & & & Sprain & $\mathrm{x}$ ray/USG & ATFL Sprain & Sport.Rehab. & 21 \\
\hline 44 & 20 & M & $\mathrm{R}$ & $\mathrm{T}$ & $\mathrm{P} / \mathrm{P}$ & $\mathrm{R}$ & & & Strain & x ray/USG & Syndesmotic Injury & Sport.Rehab. & 30 \\
\hline 45 & 28 & $M$ & $\mathrm{~L}$ & $M$ & $\mathrm{P} / \mathrm{P}$ & $\mathrm{L}$ & & & Sprain & x ray/USG & ATFL sprain & Sport.Rehab. & 21 \\
\hline 46 & 24 & $M$ & $\mathrm{R}$ & $\mathrm{T}$ & Tripping & & & $\mathrm{R}$ & Overuse & MRI & Posterior impingement & Surg & 60 \\
\hline 47 & 25 & M & $\mathrm{L}$ & $T$ & $\mathrm{P} / \mathrm{P}$ & L & & & Sprain & x ray/USG & ATFL Sprain & Sport.Rehab. & 21 \\
\hline 48 & 25 & $M$ & L & $M$ & Kicking & L & & & Sprain & x ray/USG & ATFL Sprain & Sport.Rehab. & 21 \\
\hline 49 & 20 & $M$ & $\mathrm{R}$ & M & $\mathrm{P} / \mathrm{P}$ & $\mathrm{R}$ & & & Sprain & x ray/USG & ATFL rupture & Sport.Rehab. & 30 \\
\hline 50 & 17 & M & $\mathrm{R}$ & M & $\mathrm{P} / \mathrm{P}$ & & $R$ & & Fx & $\mathrm{x}$ ray & $3^{\text {rd }}$ metatarsal stress fx. & Sport.Rehab. & 75 \\
\hline 51 & 29 & M & $\mathrm{R}$ & $\mathrm{T}$ & Shooting & & & $R$ & $F x$ & USG & Achilles tendinopathy & Sport.Rehab. & 30 \\
\hline 52 & 17 & M & $\mathrm{R}$ & $T$ & Overuse? & & $R$ & & Fx & $\mathrm{x}$ ray & 4th metatarsal stress $\mathrm{fx}$. & Cast & 90 \\
\hline 53 & 25 & M & $\mathrm{R}$ & $\mathrm{T}$ & $\mathrm{P} / \mathrm{P}$ & & $R$ & & $F x$ & $\mathrm{x}$ ray & 3rd metatarsal stress $\mathrm{fx}$. & Sport.Rehab. & 75 \\
\hline 54 & 29 & M & $\mathrm{R}$ & M & $\mathrm{P} / \mathrm{P}$ & $R$ & & & Sprain & x ray/USG & ATFL Sprain & Sport.Rehab. & 21 \\
\hline 55 & 21 & M & L & M & $\mathrm{P} / \mathrm{P}$ & L & & & Sprain & x ray/USG & ATFL Sprain & Sport.Rehab. & 21 \\
\hline 56 & 24 & M & L & $\mathrm{T}$ & Overuse & & & $\mathrm{L}$ & Overuse & USG & Achilles tendinopathy & Sport.Rehab. & 21 \\
\hline 57 & 23 & M & L & M & Landing & L & & & Sprain & USG & ATFL Sprain & Sport.Rehab. & 15 \\
\hline 58 & 25 & M & $\mathrm{R}$ & $\mathrm{T}$ & $\mathrm{P} / \mathrm{P}$ & $\mathrm{R}$ & & & Sprain & x ray/USG & ATFL Sprain & Sport.Rehab. & 21 \\
\hline 59 & 27 & M & $\mathrm{R}$ & M & Landing & $\mathrm{R}$ & & & Sprain & x ray/USG & ATFL Sprain & Sport.Rehab. & 21 \\
\hline 60 & 20 & $M$ & $\mathrm{~L}$ & $M$ & $\mathrm{P} / \mathrm{P}$ & $\mathrm{L}$ & & & Sprain & USG & ATFL Sprain & Sport.Rehab. & 15 \\
\hline 61 & 22 & M & $\mathrm{R}$ & M & $\mathrm{P} / \mathrm{P}$ & $\mathrm{R}$ & & & Strain & x ray/USG & Syndesmotic Injury & Sport.Rehab. & 21 \\
\hline 62 & 25 & $\mathrm{~F}$ & $\mathrm{R}$ & M & Jumping & & & $\mathrm{R}$ & Overuse & USG/MRI & Achilles rupture & Surg & 150 \\
\hline 63 & 22 & $\mathrm{~F}$ & $\mathrm{R}$ & $M$ & Landing & & $\mathrm{R}$ & & Contusion & x ray/MRI & Contusion/ Cuboid & Sport.Rehab. & 15 \\
\hline 64 & 33 & $\mathrm{~F}$ & $\mathrm{R}$ & M & Jumping & $\mathrm{R}$ & & & Sprain & x ray/USG & ATFL Sprain & Sport.Rehab. & 30 \\
\hline 65 & 17 & $\mathrm{~F}$ & $\mathrm{R}$ & $\mathrm{T}$ & Jumping & $\mathrm{R}$ & & & Sprain & x ray/USG & ATFL Sprain & Sport.Rehab. & 21 \\
\hline 66 & 27 & $\mathrm{~F}$ & $\mathrm{R}$ & $\mathrm{T}$ & Overuse & & & $R$ & Overuse & USG & Plantar fasciitis & Sport.Rehab. & 15 \\
\hline
\end{tabular}

Table 1: Patients demographics and characteristics. (Dom. Ext.= Dominant extremity, $M=M a l e, F=F e m a l e, R=R i g h t, L=L e f t, T=T r a i n i n g, M=M a t c h, P / P=P l a y e r-t o-p l a y e r$ contact, J=Jumping, Tck=Being tackled, K/S=Kicking and shooting, A=Anterior, $\mathrm{P}=$ Posterior, $\mathrm{M}=$ Medial, L=Lateral, Fx=Fracture, Surg=Surgery, Arth=Arthroscopy).

be the gold standard in a future scientific research in determination of return to play after ankle injury. The other weakest point of the study is the decision to return the athlete to play was made by one single clinician using subjective criteria.

Prevention of these serious ankle/foot injuries in professional soccer players should receive considerable attention, given the almost 2 months time away from the field that results. The development of effective prevention programs first involves collecting detailed information on the injury mechanism $[3,7,12]$. A soccer-specific injury reporting system with uniform diagnostic and return-to-play criteria should be developed and widely implemented [3,26]. Videobased studies are ideal for documenting injury mechanisms, but not for establishing the final diagnosis or time lost to play. The Orchard OSIFC model [27], the Oslo group's model, the ICD-10 coding system and the UEFA model can be used for establishing uniform diagnostic criteria [3].

\section{Take Home Message}

We feel that the UEFA model is the best of these for reporting injuries in epidemiological studies. Even with optimal operative and rehabilitative therapy, foot and ankle injuries among professional soccer players result in a lengthy time away from the field, a loss to their team. Efforts to minimise these injuries and time away from play needs to begin with a comprehensive plan for prospectively collecting data for long-term comparison studies.

\section{References}

1. Junge A, Dvorak J, Graf-Baumann T (2004) Football injuries during the World Cup 2002. Am J Sports Med 32: 23S-27S.

2. Dvorak J, Junge A (2000) Football injuries and physical symptoms. A review of the literature. Am J Sports Med 28: S3-S9.

3. Hagglund M, Walden M, Bahr R, Ekstrand J (2005) Methods for epidemiologica study of injuries to professional football players: developing the UEFA model. Br J Sports Med 39: 340-346.

4. Giza E, Fuller C, Junge A, Dvorak J (2003) Mechanisms of foot and ankle injuries in soccer. Am J Sports Med 31: 550-554

5. Injuryupdate.com

6. Larsen E, Jensen PK, Jensen PR (1990) Long-term outcome of knee and ankle injuries in elite football. Scan J Med Sci Sports 9: 285-289.

7. Andersen TE, Floerenes TW, Arnason A, Bahr R (2004) Video analysis of the mechanisms for ankle injuries in football. Am J Sports Med 32: 69-79.

8. Andersen TE, Tenga A, Engebretsen L, Bahr R (2004) Video analysis of injuries and incidents in Norwegian professional football. Br J Sports Med 38: 626-631.

9. Arnason A, Tenga A, Engebretsen L, Bahr R (2004) A prospective video-based analysis of injury situations in elite male football. Am J Sports Med 32: 14591465.

10. Chomiak J, Junge A, Peterson L, Dvorak J (2000) Severe injuries in football players: influencing factors. Am J Sports Med 28: S58-S68.

11. Hawkins RD, Hulse MA, Wilkinson C, Hodson A, Gibson M (2001) The 
association football medical research programme: an audit of injuries in professional football. Br J Sports Med 35: 43-47.

12. Woods C, Hawkins RD, Hulse M, Hodson A (2003) The Football Association Medical Research Programme: An audit of injuries in professional football: An analysis of ankle sprains. Br J Sports Med 37: 233-238.

13. Wong $\mathrm{P}$, Hong $\mathrm{Y}$ (2005) Soccer injuries in the lower extremities. Br J Sports Med 39: 473-482.

14. Orava S (1980) Exertion injuries due to sports and physical exercise. A clinical and statistical study of nontraumatic overuse injuries of the musculoskeletal system of athletes and keep-fit athletes. Thesis: University of Oulu, Finland.

15. Stiell IG, McKnight RD, Greenberg GH, McDowell I, Nair RC, et al. (1994) Implementation of the Ottawa ankle rules. JAMA 271: 827-832.

16. Hawkins RD, Fuller CW (1999) A prospective epidemiological study of injuries in four English professional football clubs. Br J Sports Med 33: 196-203.

17. Ekstrand J, Gillquist J (1983) Soccer injuries and their mechanisms: a prospective study. Med Sci Sports Exerc 15: 267-270.

18. Miller RA, DeCoster TA, Mizel MS (2005) What's new in foot and ankle surgery? J Bone Joint Surg Am 87: 909-917.

19. Cretnik A, Frank A (2004) Incidence and outcome of rupture of the Achilles tendon. Wien Klin Wochenschr 116: 33-38.
20. Orchard J (2003) Management of muscle and tendon injuries in footballers. Aust Fam Physician 32: 489-493.

21. Kannus P and Natri A (1997) Etiology and pathophysiology of tendon ruptures in sports. Scand J Med Sci Sports 7: 107-112.

22. Mahieu NN, Witvrouw E, Stevens V, Van Tiggelen D, Roget $P$ (2006) Intrinsic risk factors for the development of Achilles tendon overuse injury. A prospective study. Am J Sports Med 34: 226-235.

23. Woods C, Hawkins RD, Hulse M, Hodson A (2002) The Football Association Medical Research Programme: an audit of injuries in professional football: analysis of preseason injuries. Br J Sports Med 36: 436-441.

24. Hoy K, Lindblad BE, Terkelsen CJ, Helleland HE, Terkelsen CJ (1992) European soccer injuries. A prospective epidemiologic and socioeconomic study. Am J Sports Med 20: 318-322.

25. Ekstrand J (1982) Soccer injuries and their prevention. Linköping: Department of Surgery, Linköping University.

26. Ekstrand J, Karlsson J (2003) The risk for injury in football. There is a need for a consensus about definition of injury and the design of studies. Scand J Med Sci Sports 13: 147-149.

27. Orchard J (1993) Orchard Sports Injury Classification System (OSICS). Sports Health 11: 39-41.
This article was originally published in a special issue, Sport Management handled by Editor(s). Dr. Kamal Bali, Epworth Hospital, Australia 